\title{
Preliminary Design of Electric Cable Heating System
}

\author{
Huang Chaogang ${ }^{1}$, a , Zheng Zhenyi ${ }^{1},{ }^{b}$, Ma Qiang ${ }^{1 *},{ }^{*}$, Xiang Duoshu $^{2},{ }^{d}$ \\ ${ }^{1}$ Hubei University of Technology, Technology research center of ecological road engineering, \\ Wuhan, Hubei, 430068, China; \\ ${ }^{2}$ Wuhan Max thermal energy technology co. LTD Hubei, 430000, China \\ a504518118@qq.com, b1101631041@qq.com, maqiang927@163.com, d651252183@qq.com
}

\begin{abstract}
Keywords: electric heating cable; snow-melting deicing; preliminary design; cable
Abstract. On the basis of the research status of the snow-melting and the application of the electric heating cable, the preliminary design of the heating system and the control system of electric heating cable are investigated. Cable and pavements and the laying way of cable heating system and the working principle are introduced. Some important problems of the heating cable snow-melting deicing are studied. Heat transfer of system, power, laying spacing, temperature measurement and control system design are also explored. It provides reference for engineering practice.
\end{abstract}

\section{Introduction}

The heating cable has advantages in safe, durable, low operation cost, good thermal stability, convenience and environmental protection, which have make it used and researched in many engineering fields. For example,Kong Xiang-qiang obtained the density distribution of thermometer heat flow in floor and main factors influencing working performance of heating cable ground heating system ${ }^{[1,2]}$. Zhuang Meng described the application and performance requirements of heating cables ${ }^{[3]}$. Luo Yanling introduced the development status, working principle, performance, structure and characteristics of automatic temperature heating cable ${ }^{[4]}$. Li Yanfeng put forward the scheme of insulation and electric tracing antifreezing, and analyzed its $\operatorname{cost}^{[5]}$. Many scholars have also studied the heating cable's radiation heating in floor ${ }^{[6,7]}$.

Heating cables are used for road ice melting in many countries, but there are few of the relevant standards and reports on some of the major issues. To research the application of cable heating system in snow-melting engineering,the initial installation design and lay the foundation for engineering practice is introduced herein,according to the road design specifications and cable laying specifications.

\section{Introduction of cable}

The cable is made of the use of current through the conductive material to produce resistance by the resistance to the conversion of electrical energy into the principle of heat. When the cable is energized, the electric energy is converted into heat energy which is mainly distributed in the form of radiation and convection, and the proportion of convective heat transfer is about $33 \%$ to $51 \%$.

As shown in figure 1, the cable is generally composed of a heating element, insulation layer, grounding wire, metal braided layer and PVC sheathing compound, etc.Metal braided layer is mainly used to shield the internal electromagnetic waves from the wire, reduce the interference of electronic equipment, and also have the function of grounding protection. The sheath is mainly used 
to improve the compressive strength and tensile strength and make the cable withstand the use of the pavement.

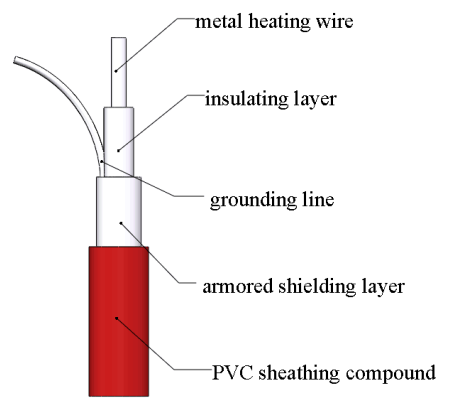

Fig. 1 The basic structure of cable

The physical characteristics of each component of the cable guarantee its following advantages: (1) high heat efficiency and long life; (2) good safety, no leakage or short circuit; (3) no electromagnetic pollution; (4) having certain mechanical strength; (5) a certain temperature control measures to prevent surface temperature exceeds the safety requirements.

\section{Preliminary Design of Cable Heating System}

Cable arrangement. The structure of the cable applied to the road is that spread in the concrete. There are many kinds of cable in the structure layer, and three kinds of linear, reciprocating and rotating types.

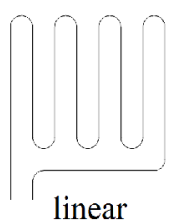

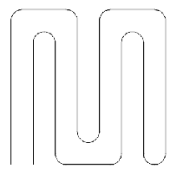

reciprocating

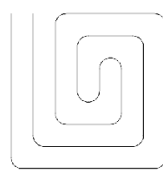

rotational

Fig. 2 cable arrangement

A layout of linear type, as shown in figure 3 . The cable is spread in an area of $640 \mathrm{~mm} \times 640 \mathrm{~mm}$.
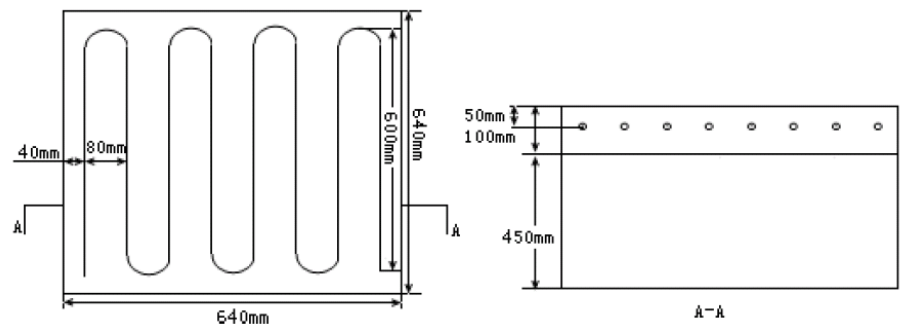

Fig. 3 model of cable laying in structure layer

Working principle of cable heating system. The basic ideas of melting snow in cable heating system are as follows: In order not to affect the bearing strength of the road, a $10 \mathrm{~cm}$ concrete layer can be applied to the pavement. In this layer, according to the process requirements laying a certain power cable, and the thickness is estimated to be about $50 \mathrm{~mm}$. When the power is connected, the cable generates heat, the temperature increases, while the heat diffuses form the concrete layer to the ice and snow, so that the temperature rise to ice melting point. At the same time,the insulation layer is laid beneath the structure layer to prevent heat transfer. In this way, the heat generated by the cable is absorbed mainly by the ice and snow on the pavement, so as to ensure the efficient melting of snow under the condition of low energy consumption. 
System heat transfer analysis. According to the basic theory of heat transfer, the heat transfer process of pavement structure and surface and surrounding air includes three basic heat transfer modes of heat conduction, convection and radiation, as shown in figure. 4.

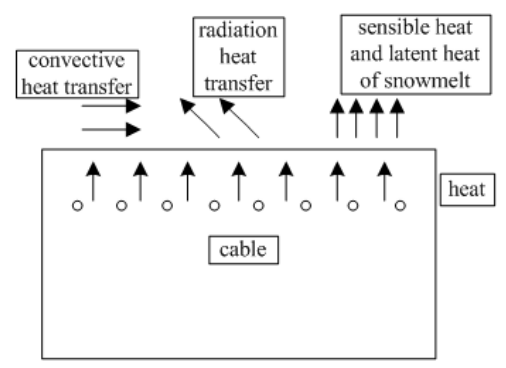

Fig. 4 heat transfer mechanism of snow melting in cable heating system

The cable transfers heat to the pavement by heat conduction, convection heat transfer between the pavement and the cold air, and the temperature difference between the pavement and the surrounding environment, so the radiation heat transfer between them. In addition to convection heat transfer and radiation heat transfer, the surface heat of the structural layer is absorbed by the snow, which is used for the purpose of snow melting and ice melting.

The heat absorbed by snow-melting. There is a phase transition heat conduction problem when melting into water. The main features of such problems: The governing equation is a heat conduction equation, and there is a two-phase moving interface over time that absorbs or releases heat at that interface, which is latent heat.The heat absorbed by the melting snow includes the heat absorbed from the negative temperature to 0 degrees centigrade and latent heat.

$$
q_{\mathrm{s}}=\rho_{\mathrm{s}} S\left(C_{\mathrm{w}} t_{0}-C_{\mathrm{s}} t_{\mathrm{f}}\right)+\rho_{\mathrm{s}} S H_{\mathrm{fg}}
$$

Where: $\rho_{\mathrm{s}}$ refers to the density of the $\operatorname{snow}\left(\mathrm{kg} / \mathrm{m}^{3}\right) ; \mathrm{C}_{\mathrm{w}}, \mathrm{C}_{\mathrm{s}}$ is the specific heat for snow and water $\mathrm{kJ} /\left(\mathrm{kg}^{\circ} \mathrm{C}\right)$; For delayed snowmelt, $\mathrm{S}$ is the snow-melting speed, For real time snowmelt, $S$ is snowfall rate, which is given by precipitation $(\mathrm{mm} / \mathrm{s}) ; \mathrm{t} 0, \mathrm{tf}$ refers to the temperature of snow melting into water and Snowfall temperature, respectively $\left({ }^{\circ} \mathrm{C}\right) ; \mathrm{H}_{\mathrm{fg}}$ is the latent heat of water at 0 degrees centigrade $(\mathrm{kJ} / \mathrm{kg})$.

Radiation heat transfer. Radiation heat transfer is the process of energy transfer through the mutual radiation and absorption of heat rays when the temperature of two objects is different. The calculation formula of heat flux for radiative heat transfer is as follows:

$$
q_{r}=\varepsilon C_{b}\left\{(t+273)^{4}-\left(t_{f}+273\right)^{4}\right\}
$$

Where: $\varepsilon$ is surface heat emissivity, for cement concrete pavement, it's generally 0.89 , for snow, it's usually $0.8 . C_{\mathrm{b}}$ is blackbody radiation coefficient $5.67 \times 10^{-8}, \mathrm{w} /\left(\mathrm{m}^{2} \mathrm{k}^{4}\right) ; t$ is surface temperature $\left({ }^{\circ} \mathrm{C}\right), t_{f}$ is air temperature $\left({ }^{\circ} \mathrm{C}\right)$.

Convective heat transfer. Convective heat transfer includes natural convection, forced convection and mixed convection. Calculation formula of heat flux for convective heat transfer is as follows:

$$
q_{f}=h\left(t-t_{f}\right)
$$

Where: $h$ is convection heat transfer coefficient $\left(\mathrm{w} / \mathrm{m}^{2} \mathrm{k}\right), t$ is pavement surface temperature $\left({ }^{\circ} \mathrm{C}\right), t_{f}$ is air temperature $\left({ }^{\circ} \mathrm{C}\right)$.

Installation power. The greater the installation power is, the more heat is generated by the cable in 
unit time, which can ensure the inside and surface of the pavement structure are raised to the required temperature in a short time, reduce preheating time and improve deicing and snow melting effect. However, the larger installation power, will increase the supporting power load, and the cost of ancillary and operating facilities. Meanwhile, the increase of installation power requires a shortened distance between cables, it will reduce of heat transfer efficiency, shorten the service life of cable.How much power should be adopted depends on the size of the physical parameters of the structural layer, environmental conditions, the requirements of preheating time and other factors, which should be comprehensively considered.

The whole system carries out energy exchange with the outside through convection heat transfer, radiation heat transfer, sensible heat and latent heat of snow melt absorption and other ways. In order to ensure the system to achieve the best real-time snow melt effect, the cable installation power and system output heat must be kept constant. The cable installation power is obtained:

$$
q=q_{s}+(1-A r)\left(q_{r}+q_{f}\right)
$$

Where: $A \mathrm{r}$ is the ratio of ice and snow area to the whole area .When $A \mathrm{r}=0$, the road surface without ice; when $A r=1$, the road surface all covered with snow and ice.

\section{Preliminary Design of Control System}

Based on the above analysis, the change of the surrounding environment, such as the unceasing change of wind speed, wind direction, the amount of snow varies, the temperature changes in the same day, which will cause the surface and the surrounding environment heat changes.Therefore, concerned all the factors mentioned above, it is necessary to adopt an appropriate control system. For the cable heating system, the control mode is directly related to it's operation stability and operation cost when melting snow, and usually, the cable heating system for snow melt is a large area of heating. Therefore, the centralized control of the control box must be adopted.

When the system is used for real-time snow melting,only when the concrete surface temperature reaches $2^{\circ} \mathrm{C} \sim 3^{\circ} \mathrm{C}$ can best effect be gotten. Therefore, in the control system, the surface temperature of the pavement is taken as the controlled quantity, the amount of heat generated per unit time of the cable is the manipulated variable.To study the cable heating system for snow melt control problems, the measurement of the surface temperature of the road surface should be firstly considered, and then the design of the control device.

Temperature measurement. The temperature can't be measured directly, and only by means of the heat exchange between different objects of hot and cold and the properties of some heat treatment of objects with the varying degrees of cold and hot, can it be measured. There are two types of temperature measuring instruments: contact type and non-contact type, which the former temperature sensor is directly contacted with the measured medium and the latter is not .

Compared with contact thermometers,non-contact thermometers is easier to implement, because of two reasons: First, convenient to construction, such as radiation-type thermometer can be set on both sides of the road, thus the temperature field of the pavement surface is not destroyed; Second, avoiding the damage to the thermometer caused by the movement load. Combined with the characteristics of the thermometer, non-contact thermometer is more suitable for measuring the surface temperature of the pavement.

Control scheme design. Under the setting installation power, to make the system operating conditions best, it's essential to adopt a reasonable control scheme. Therefore, the control scheme should involve the monitoring of the surface temperature of the road, the design and evaluation of the control system scheme and other issue. 
The general process of snowmelt control system is shown in figure 5. When the snow weather forecast has been received, analyzing the time of opening the system in advance through the temperature, wind speed and other meteorological conditions, and then, the cable heating system is opened by the intelligent control system.In the initial stage of opening, due to the large deviation between the actual surface temperature and the target temperature, the controller will set the working state to open. When the temperature continues to rise over $3^{\circ} \mathrm{C}$, the working state is closed. As the heat transfer between the pavement surface and the environment, the temperature decreases continuously. When the pavement surface temperature is lower than $3{ }^{\circ} \mathrm{C}$, the working state is resumed to be opened, so reciprocating cycle.

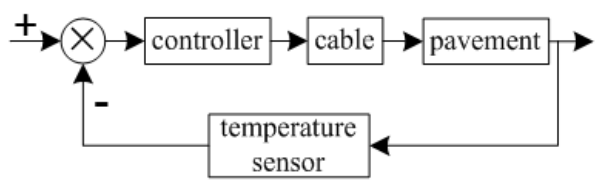

Fig. 5 Flow chart of control system

\section{Conclusions}

According to the basic theory of heat transfer, This paper analyzes the heat transfer of cable heating system, and the calculation formula of the cable heating system installation power under different conditions is obtained. When the type of cable is selected and the installation power is determined, the distance between cables can be determined, and the preliminary design of the cable heating system is put forward. In different cases, in order to maintain the temperature of road surface from $2^{\circ} \mathrm{C}$ to $3{ }^{\circ} \mathrm{C}$, the output power is not the same, therefore, the control scheme of cable heating system is put forward.

\section{Acknowledgement}

The work in this paper is supported by grants from National Key R\&D Program of China(No.2016YFC0502208), and National Natural Science Foundation of China(NSFC) (No.51678223). The authors would like to express their appreciation to these financial assistances.

\section{REFERENCES}

[1] Kong Xiang-qiang, Li Ying. Numerical study on heat transfer of electrical radiant floor heating System on the passenger train[J].Journal of Engineering Thermophysics,2003,24(2): 316-318.

[2] Kong Xiang-qiang, Li Ying. Experimental study on low temperature heating cable ground radiant heating system for the passenger train[J].Journal of HV\&AC. 2004,34(11): 10-14.

[3] Zhuang Meng, Liu Guangjun. Category and application of heating cables[J]. Electric Wire \& Cable, 2002.

[4] Luo Yan-ning, Huang Xin-wu. Self-regulating heating cables for antifreezing insulation [J]. Portland Technology. 2002,5: 14-16.

[5] Li Yan-feng, Jia Heng. The dynamic operation characteristics and energy conservation research of the new type pipeline antifreeze scheme [J]. Building Energy \& Environment. 2002,1: 11-14.

[6] Herbertr. Bailey. An Experimental Comparison of Energy Requirements for Space Heating with Radiant and Convective Systems[J]. In : ASHRAE Trans.1980,86(1): 73-78.

[7] Haruo Hanibuchi, Shuichi Hokoi. Basic Study of Radiative and convective Heat Exchange in 
a Room with Floor Heating[J]. ASHRAE Transactions. 1998(104): 1098-1105. 